OPEN ACCESS

Edited by:

Assunta Venuti,

International Agency for Research on

Cancer (IARC), France

Reviewed by:

Aldo Venuti,

Regina Elena National Cancer Institute, Italy

Katia Zanier

UMR7242 Biotechnologie et

Signalisation Cellulaire, France

*Correspondence:

Simona Citro

simona.citro@ieo.it

Susanna Chiocca

susanna.chiocca@ieo.it

${ }^{\dagger}$ Lead Author

Specialty section:

This article was submitted to

Virus and Host,

a section of the journal

Frontiers in Cellular and Infection

Microbiology

Received: 23 January 2020 Accepted: 18 March 2020

Published: 08 April 2020

Citation

Citro S, Bellini A, Medda A, Sabatini ME, Tagliabue M, Chu F and

Chiocca S (2020) Human Papilloma Virus Increases $\Delta N p 63 \alpha$ Expression in Head and Neck Squamous Cell

Carcinoma

Front. Cell. Infect. Microbiol. 10:143 doi: $10.3389 / f c i m b .2020 .00143$

\section{Human Papilloma Virus Increases $\Delta$ Np63 $\alpha$ Expression in Head and Neck Squamous Cell Carcinoma}

\author{
Simona Citro ${ }^{*}$, Alice Bellini ${ }^{1}$, Alessandro Medda ${ }^{1}$, Maria Elisa Sabatini ${ }^{1}$, \\ Marta Tagliabue ${ }^{2}$, Francesco $\mathrm{Chu}^{2}$ and Susanna Chiocca ${ }^{1 \star t}$ \\ ${ }^{1}$ Department of Experimental Oncology, IEO, European Institute of Oncology IRCCS, Milan, Italy, ${ }^{2}$ Division of Otolaryngology \\ Head \& Neck Surgery, IEO, European Institute of Oncology IRCCS, Milan, Italy
}

P63, and in particular the most expressed $\Delta$ Np63 $\alpha$ isoform, seems to have a critical role in the outcome of head and neck cancer. Many studies have been conducted to assess the possible use of p63 as a prognostic marker in squamous cell carcinoma cancers, but the results are still not well-defined. Moreover, a clear relationship between the expression of $\Delta \mathrm{Np63 \alpha}$ and the presence of high-risk HPV E6 and E7 oncoproteins has been delineated. Here we describe how $\Delta$ Np63 $\alpha$ is mostly expressed in HPV-positive compared to HPV-negative head and neck cancer cell lines, with a very good correlation between $\triangle N p 63 \alpha$ mRNA and protein levels.

Keywords: head and neck cancer, head and neck carcinoma, HPV, HPV16, p63

\section{INTRODUCTION}

The p53 family of transcription factors, including p53 (TP53), p63 (TP63), and p73 (TP73), are key players in tumor development and formation (Vousden and Prives, 2009). While the p53 gene is mutated or lost in the majority of human cancers, neither p63 nor p73 show frequent somatic mutations in neoplasia (Deyoung and Ellisen, 2007). All three p53 family members encode proteins with strong homologies to $\mathrm{p} 53$, not so much in terms of primary sequence, but in overall domain structure and conformation, with high homology in the DNA-binding domains. p63 and p73 are expressed from two distinct promoters, which produce two isoforms either containing or lacking the N-terminal transactivation domain (TAp63/p73 and DNp63/p73, respectively) (Deyoung and Ellisen, 2007). Alternative splicing of the $3^{\prime}$ end of the TA and $\Delta$ Np63 mRNAs produces the $\alpha$, $\beta$, and $\gamma$ isoforms. $\Delta \mathrm{Np} 63 \alpha$ is the most abundant isoform detected in the basal layer of mucosa, skin, and other epithelial tissues and it is overexpressed in up to $80 \%$ of primary Head and Neck Cancers (HNC).

During development, $\triangle \mathrm{Np} 63 \alpha$ expression is restricted to epithelial stem cells and the undifferentiated basal layer of stratified epithelia and is critical for the development and maintenance of stratified epithelial tissues (Oh et al., 2011). Nevertheless, $\Delta \mathrm{Np} 63 \alpha$ functions as a potent oncogene in squamous cell carcinomas (SCCs) of diverse origins (Rocco et al., 2006; Yang et al., 2011). In particular, we have recently shown how $\Delta \mathrm{Np} 63 \alpha$ is critical for cellular proliferation and migration in HNC cell lines (Citro et al., 2019).

HNC affect $\sim 600,000$ patients per year worldwide and is the sixth leading cancer by incidence. Smoking is mainly implicated in the rise of HNC in developing countries, while the human papillomavirus (HPV) is an established important risk factor in the increase of oropharyngeal cancers in developed countries (Ang et al., 2010; Sabatini and Chiocca, 2019; Sandulache et al., 2019). 
Although HPV-positive and HPV-negative HNC are characterized by etiological, biological and clinical heterogeneity, the same therapeutic protocol, comprising surgery, radiation and chemotherapy, is used. In this study we characterized a different pattern of expression of $\Delta \mathrm{Np} 63 \alpha$ in HNC cell lines, comparing HPV-positive and HPV-negative HNC cell lines. We clearly show an increase of both $\triangle \mathrm{Np} 63 \alpha \mathrm{mRNA}$ and protein levels in HPV-positive compared to HPV-negative cell lines, which is dependent on the presence of the HPV E6 and E7 oncoproteins.

\section{METHODS}

\section{Cell Culture}

HNC cell lines were acquired from different sources (Brenner et al., 2010) and were already accurately described and cited (Steenbergen et al., 1995; Ballo et al., 1999; Ragin et al., 2004; White et al., 2007; Brenner et al., 2010; Tang et al., 2012) in our previous study (Citro et al., 2019). Every 6 months all cell lines were authenticated by short tandem repeat profiling and tested for mycoplasma contamination. Skin biopsies were collected via standardized operative procedures approved by European Institute of Oncology Ethical Board. Informed consent was obtained from all patients (donors). Adult human epidermal keratinocytes (HKs) were prepared and maintained as previously described (Pozzebon et al., 2013; Mattoscio et al., 2017). Briefly, skin biopsies from donors were digested with Dispase $(10 \mathrm{U} / \mathrm{mL}$; Gibco) for $4 \mathrm{~h}$ at $37^{\circ} \mathrm{C}$ to remove the epidermis, followed by a trypsinization step (Trypsin $500 \mathrm{mg} / \mathrm{L}$ ) for $30 \mathrm{~min}$ at $37^{\circ} \mathrm{C}$ to obtain isolated cells. Primary cultures of the isolated cells were then maintained in Keratinocyte Serum-Free Medium (KSFM; Gibco) containing bovine pituitary extract (BPE, $30 \mu \mathrm{g} / \mathrm{mL}$; Gibco) and epidermal growth factor (EGF, $0.2 \mathrm{ng} / \mathrm{mL}$; Gibco). Cells from passages $2-5$ were used for the experiments. All cells were cultured at $37^{\circ} \mathrm{C}$ in a $5 \% \mathrm{CO}_{2}$ buffered incubator.

\section{Transduction, Transfection, and Plasmids}

pLXSN HPV16E6/E7 and empty vector were previously described (Mattoscio et al., 2017). For retroviral transduction, plasmids were transfected into Phoenix Ampho cells by calciumphosphate method. The following day, HKs were transduced with retroviral supernatants for $6 \mathrm{~h}$ at $37^{\circ} \mathrm{C}$ for 2 days and selected with G-418 Sulfate (Gibco) for 1 week and finally collected for RNA extraction or WB (Mattoscio et al., 2017). HPV-positive HNC cell lines were transfected with Lipofectamine 2000 (Thermo Fisher Scientific) with siLuciferase or E6/E7 siRNAs (Mattoscio et al., 2017) following manufacturers' instruction. $72 \mathrm{~h}$ after transfection, cells were collected for WB analysis.

\section{Cell Lysis and Western Blot}

Cells were lysed in E1A buffer (50 mM HEPES pH7, $250 \mathrm{mM}$ $\mathrm{NaCl}, 0.1 \% \mathrm{NP}-40$, proteases inhibitors, $0.5 \mathrm{mM}$ NEM, $0.5 \mathrm{mM}$ $\mathrm{NaF}$, and $2 \mathrm{mM} \mathrm{Na}_{3} \mathrm{VO}_{4}$ ). After lysis, an equal amount of protein for each sample was resuspended in denaturing sample loading buffer, separated on SDS-PAGE gel and immunoblotted with the indicated antibodies. The following antibodies were used: p63 (mouse, Abcam), HPV16 E7 and p53 (mouse, Santa Cruz), and Vinculin (mouse, Sigma Aldrich) as loading control. Membranes were then incubated with the appropriate horseradish peroxidase (HRP) secondary antibodies and the signal was acquired with Chemidoc (Bio-Rad).

\section{RT-qPCR}

RNA was extracted from cells with the Quick-RNA MiniPrep kit (ZYMO RESEARCH). cDNA was generated by reverse transcription-PCR with Reverse Transcriptase (Promega). Relative levels of specific mRNAs were determined with the Fast SYBR Green detection chemistry system (Applied Biosystem). All PCR reactions were performed with a 7500 Fast Real-Time PCR system (Applied Biosystem). Ribosomal Phosphoprotein (RpPO) was used as a house-keeper gene for normalization. Densitometric analysis of the intensity of the protein bands were preformed using ImageJ software (Rasband W.S., ImageJ, U. S. National Institutes of Health), and standardized to the housekeeper levels.

\section{Statistical Analysis}

Statistical differences were evaluated using unpaired $t$-test (Graphpad Prism version 6 software).

\section{RESULTS}

\section{HPV-Positive HNC Cell Lines Expressed Higher Protein Level of $\Delta \mathrm{Np} 63 \alpha$ Compared to HPV-Negative Cell Lines}

We screened $\Delta \mathrm{Np} 63 \alpha$ protein expression in a panel of 12 cell lines, from different subsites, divided by sex and HPV status (Citro et al., 2019). Although we used a p63 antibody able to recognize all p63 isoforms, $\Delta \mathrm{Np} 63 \alpha$ is the predominant isoform expressed in HNC (Sniezek et al., 2004). Figures 1A,B showed a clear upregulation of the protein level of $\triangle \mathrm{Np} 63 \alpha$ in HPVpositive compared to HPV negative cell lines. Among the HPVpositive cell lines, UMSCC-47 lacks the expression of $\Delta \mathrm{Np} 63 \alpha$, due to the multiple integration of HPV16 at the TP63 locus, thus leading to the expression of a truncated $25-\mathrm{kDa}$ protein at the carboxyl terminus of p63 (Akagi et al., 2014). Therefore, we excluded UMSCC-47 cells in the analysis of the distribution of $\triangle \mathrm{Np} 63 \alpha$ protein expression between HPV-positive and HPVnegative $\mathrm{HNC}$ cell lines. As a result, $\triangle \mathrm{Np} 63 \alpha$ protein expression is significantly higher in $\mathrm{HPV}$-positive compared to HPVnegative HNC cell lines (Figure 1C).

\section{$\Delta$ Np63 $\alpha$ mRNA Level Is Significantly Higher in HPV-Positive Compared to HPV-Negative HNC Cell Lines}

We then assessed the mRNA of $\Delta \mathrm{Np} 63 \alpha$ by RT-qPCR in the same panel of HNC cell lines. As shown in Figure 2A HPVpositive $\mathrm{HNC}$ cell lines expressed higher levels of $\triangle \mathrm{Np} 63 \alpha$ mRNA compared to HPV-negative HNC cell lines. The same analysis performed for protein level was performed for $\Delta \mathrm{Np} 63 \alpha$ mRNA level and showed a significantly higher mRNA level in HPV- positive cell lines (Figure 2B). Moreover, as shown in Figure 2C a high correlation between $\triangle \mathrm{Np} 63 \alpha \mathrm{mRNA}$ and 

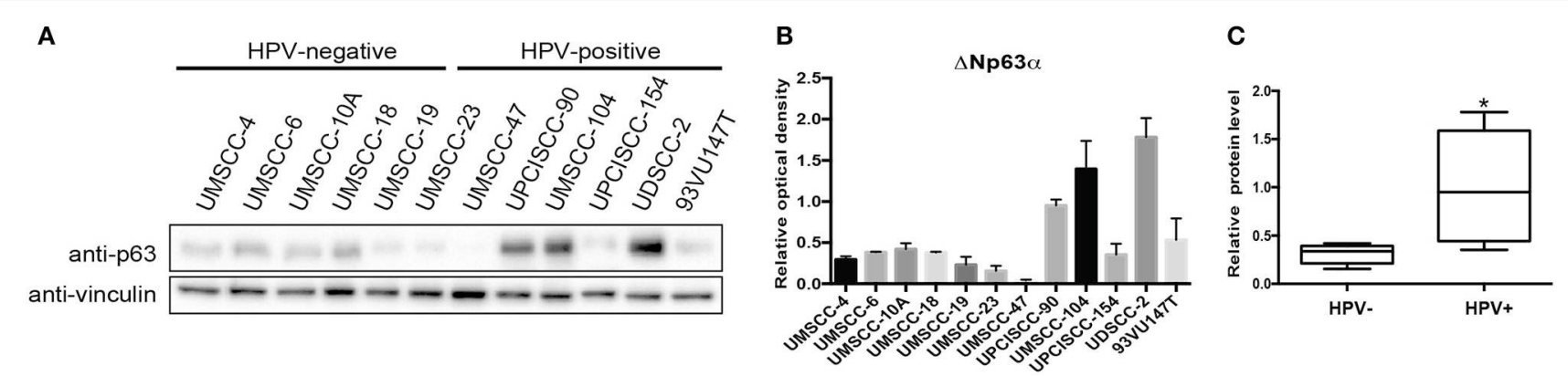

FIGURE 1 | $\triangle$ Np63 $\alpha$ protein levels are higher in HPV-positive HNC cell lines. (A) HNC cell lines were lysed and analyzed by immunoblotting with the indicated antibodies. (B) Optical density analysis of the expression of $\triangle \mathrm{Np} 63 \alpha$ from three independent western blot experiments of HNC cell lines was performed and results were normalized to loading control (vinculin) and expressed as means \pm SD. (C) Box plot showing the median and 10-90 percentiles of the optical density results showed in (B), ${ }^{*} P<0.05$ (unpaired $t$-test, calculated excluding UMSCC-47 value).

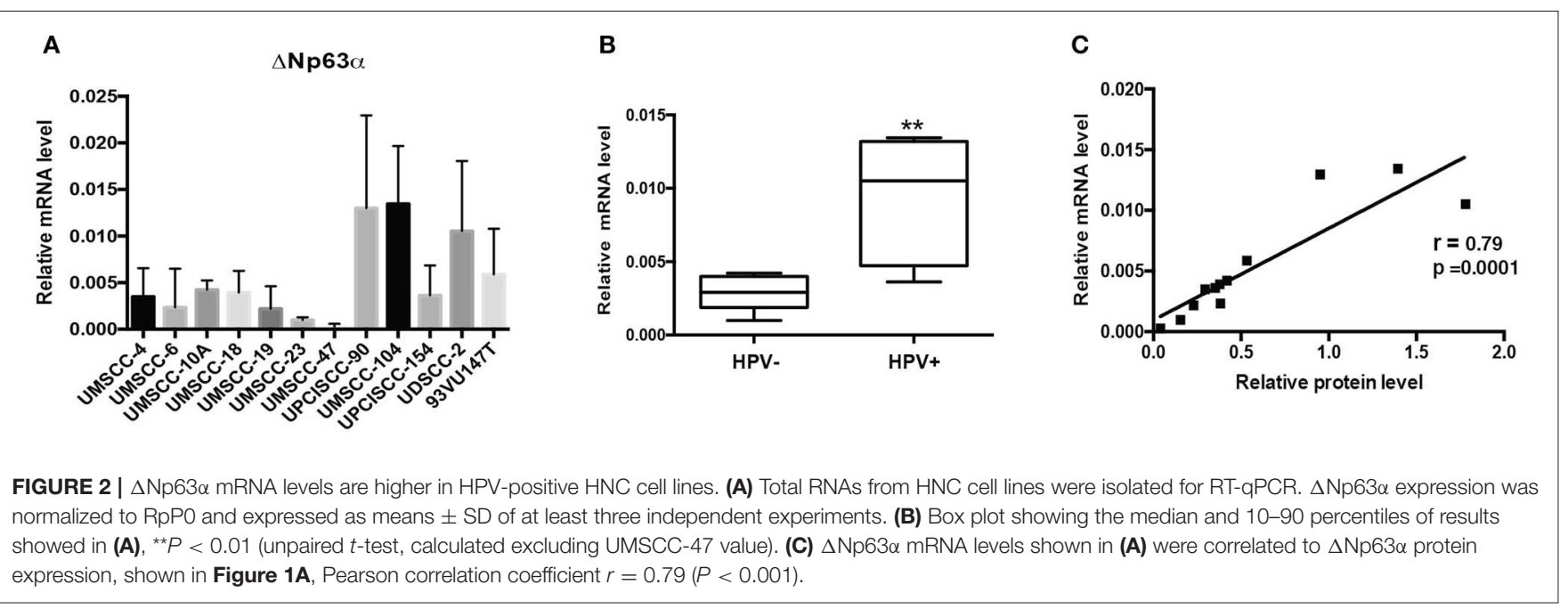

protein level is present, implicating that mRNA expression may be useful in predicting $\Delta \mathrm{Np} 63 \alpha$ protein levels.

\section{Lack of HPV16 E6/E7 Oncoproteins Decreased $\Delta \mathrm{Np} 63 \alpha$ Expression}

We then asked whether the lack of the expression of the main HPV oncoproteins had an impact on $\triangle \mathrm{Np} 63 \alpha$ expression, by silencing of E6/E7 with specific siRNA in HPV-positive HNC cell lines. As shown in Figure 3, siRNAs were efficient in depriving the oncoproteins, also validated by p53 expression upregulation due to lack of E6. Likewise, western blot analysis revealed that $\Delta \mathrm{Np} 63 \alpha$ expression was decreasing in the absence of E6/E7, showing that $\Delta \mathrm{Np} 63 \alpha$ is E6/E7 dependent. These data demonstrate that $\Delta \mathrm{Np} 63 \alpha$ expression is E6/E7 dependent in $\mathrm{HPV}$-positive HNC cell lines.

\section{$\Delta$ Np63 $\alpha$ Expression Increases in HPV16E6/E7 Transformed Human Keratinocytes (HK)}

To further corroborate the dependency of $\Delta \mathrm{Np} 63 \alpha$ expression on E6/E7, we transduced primary HK with HPV16E6/E7 retroviral

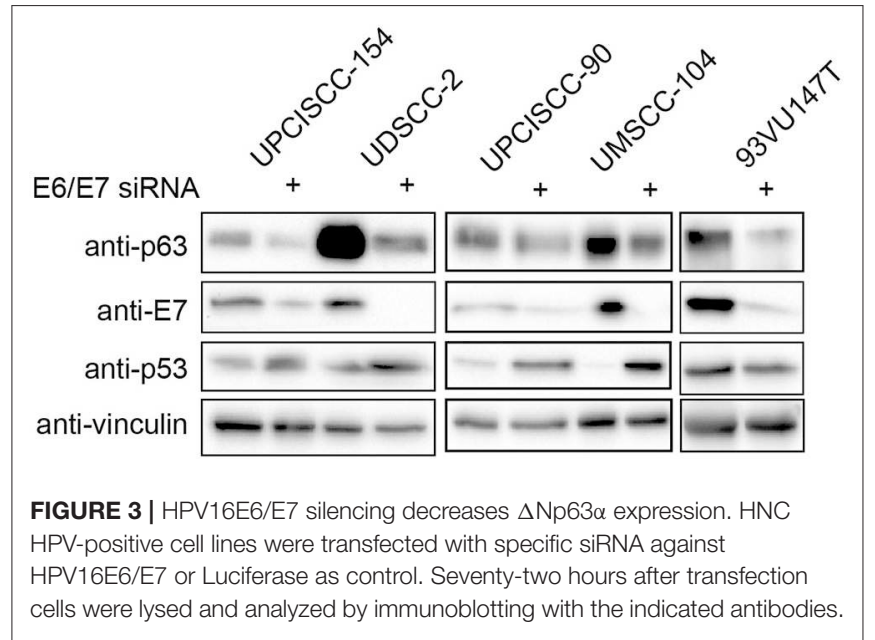

particles. Western blot analysis clearly showed an upregulation of $\Delta \mathrm{Np} 63 \alpha$ protein levels (Figure 4A). Moreover, since E6 and $\mathrm{E} 7$ are known to modulate the transcriptome to target diverse 
A

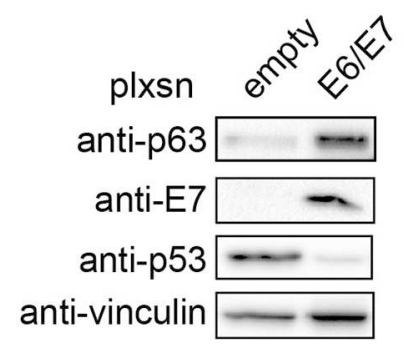

B

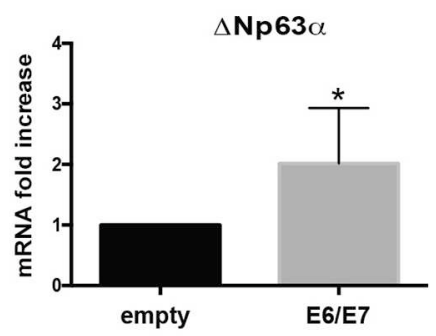

FIGURE 4 | HPV16E6/E7 transduction increases $\Delta$ Np63 $\alpha$ expression in Human Keratinocytes (HK). HK were transduced with empty or HPV16E6/E7 recombinant retroviral vectors. After selection with G418 cells were harvested. (A) Lysates were collected and analyzed by immunoblotting with the indicated antibodies. (B) Total RNAs were isolated for RT-qPCR. $\triangle$ Np63 $\alpha$ expression was normalized to RpPO. Results from five independent experiments are expressed as means \pm SD of fold changes of $\Delta$ Np63 $\alpha$ expression of HPV16E6/E7 infected cells over control (empty vector), ${ }^{\star} P<0.05$ (unpaired $t$-test).

cellular pathway, such as cell cycle and apoptosis (Tomaic, 2016), we then investigated weather E6/E7 transduction was able to increase $\Delta \mathrm{Np} 63 \alpha \mathrm{mRNA}$ levels. As shown in Figure 4B, E6/E7 $\mathrm{HK}$ had a significant higher mRNA level compared to $\mathrm{HK}$ control cells, suggesting that HPV16 is able to increase $\triangle \mathrm{Np} 63 \alpha$ at transcriptional level.

\section{DISCUSSION}

Both HPV-positive and negative tumors contain recurrent focal amplifications for $3 q 26 / 28$, a region which includes squamous lineage transcription factors, such as TP63 and SOX2, as well as the oncogene, PIK3CA (Lawrence et al., 2015). However, besides genomic amplification, the TP63 gene is not frequently mutated in HNC with only a 7\% mutation rate (Stransky et al., 2011) and in some cases, overexpression of p63 is likely to involve mechanisms independent of genomic alterations (Redon et al., 2001). Few studies have already shown that high risk HPV E6 and E7 oncoproteins are able to transcriptionally regulate TP63 gene, probably to facilitate the viral life cycle (Melar-New and Laimins, 2010; Mighty and Laimins, 2011; Srivastava et al., 2017). In this study we confirmed that HPV16 E6/E7 expression is able to regulate $\Delta \mathrm{Np} 63 \alpha$ transcriptionally, increasing both its mRNA and protein levels in transduced HK. Moreover, the link between HPV oncoproteins and $\triangle \mathrm{Np} 63 \alpha$ expression was confirmed in HNC HPV-positive cell lines where the lack of E6/E7 consistently decreased $\Delta \mathrm{Np} 63 \alpha$ protein levels. As a result we showed, to the extent of our knowledge for the first time, that $\triangle \mathrm{Np} 63 \alpha$ expression is significantly greater in HPVpositive compared to HPV-negative HNC cell lines, both at protein and mRNA levels. Moreover, we found a very high correlation between protein and mRNA $\Delta$ Np63 $\alpha$ levels in HNC cell lines, suggesting that $\Delta \mathrm{Np} 63 \alpha$ protein expression can be easily predicted from quantitative mRNA data. $\Delta \mathrm{Np} 63 \alpha$ has a clear role in promoting squamous epithelial proliferation, migration, and inflammation in HNC (Rocco et al., 2006; Yang et al., 2011; Citro et al., 2019). One study reported that high p63 expression is associated with a more aggressive phenotype and poor prognosis in oral squamous cell carcinoma (OSCC)
(Lo Muzio et al., 2005), whereas other studies either showed that impaired p63 expression could be important in neoplastic transformation of OSCC (Foschini et al., 2004) or could not find any significant association between $\mathrm{p} 63$ protein expression and survival, recurrence, or metastasis in OSCC patients (Oliveira et al., 2007). In addition, it has also been shown that high $\Delta \mathrm{Np} 63 \alpha$ protein levels accurately predict response to platinumbased chemotherapy and a favorable outcome in HNC patients (Zangen et al., 2005). Moreover, it is very well-accepted that HPV-positive HNC respond more favorably to radiation and have a more favorable prognosis compared to HPV-negative HNC (Gillison, 2004; Reid et al., 2018). Thus, further studies defining the expression of p63 in HPV-positive head and neck tumors and its association to patient survival or recurrence are needed. This might allow to use p63 as a clinical target for HPV-HNC patients, promoting the use of drugs such as HDAC inhibitors that have been shown to modulate p63 expression in HNC cell lines (Napoli et al., 2016; Citro et al., 2019).

\section{DATA AVAILABILITY STATEMENT}

The raw data supporting the conclusions of this article will be made available by the authors, without undue reservation, to any qualified researcher.

\section{ETHICS STATEMENT}

This study was carried out in accordance with the recommendations of IEO Biobank for translational medicine (B4MED). The protocol was approved by the IEO committee. All subjects gave written informed consent in accordance with the Declaration of Helsinki.

\section{AUTHOR CONTRIBUTIONS}

SCi and SCh conceptualized the study. SCi, AB, AM, MS, FC, and MT were responsible for data and materials acquisition. SCi, AM, MS, and SCh worked on the data analysis and writing and editing the review. 


\section{FUNDING}

This study was funded by Associazione Italiana per la Ricerca sul Cancro (A.I.R.C.) to SCh (IG 2015 Id.16721). SCi is currently a recipient of a Fondazione IEO-CCM fellowship and was also a FUV (Fondazione Umberto Veronesi) fellow. This work was

\section{REFERENCES}

Akagi, K., Li, J., Broutian, T. R., Padilla-Nash, H., Xiao, W., Jiang, B., et al. (2014). Genome-wide analysis of HPV integration in human cancers reveals recurrent, focal genomic instability. Genome Res. 24, 185-199. doi: 10.1101/gr.1648 06.113

Ang, K. K., Harris, J., Wheeler, R., Weber, R., Rosenthal, D. I., NguyenTan, P. F., et al. (2010). Human papillomavirus and survival of patients with oropharyngeal cancer. N. Engl. J. Med. 363, 24-35. doi: 10.1056/NEJMoa0912217

Ballo, H., Koldovsky, P., Hoffmann, T., Balz, V., Hildebrandt, B., Gerharz, C. D., et al. (1999). Establishment and characterization of four cell lines derived from human head and neck squamous cell carcinomas for an autologous tumor-fibroblast in vitro model. Anticancer Res. 19, 3827-3836.

Brenner, J. C., Graham, M. P., Kumar, B., Saunders, L. M., Kupfer, R., Lyons, R. H., et al. (2010). Genotyping of 73 UM-SCC head and neck squamous cell carcinoma cell lines. Head Neck 32, 417-426. doi: 10.1002/hed. 21198

Citro, S., Bellini, A., Miccolo, C., Ghiani, L., Carey, T. E., and Chiocca, S. (2019). Synergistic antitumour activity of HDAC inhibitor SAHA and EGFR inhibitor gefitinib in head and neck cancer: a key role for DeltaNp63alpha. Br. J. Cancer 120, 658-667. doi: 10.1038/s41416-019-0394-9

Deyoung, M. P., and Ellisen, L. W. (2007). p63 and p73 in human cancer: defining the network. Oncogene 26, 5169-5183. doi: 10.1038/sj.onc.1210337

Foschini, M. P., Gaiba, A., Cocchi, R., Pennesi, M. G., Gatto, M. R., Frezza, G. P., et al. (2004). Pattern of p63 expression in squamous cell carcinoma of the oral cavity. Virchows Arch. 444, 332-339. doi: 10.1007/s00428-0030969-x

Gillison, M. L. (2004). Human papillomavirus-associated head and neck cancer is a distinct epidemiologic, clinical, and molecular entity. Semin. Oncol. 31, 744-754. doi: 10.1053/j.seminoncol.2004.09.011

Lawrence, M. S., Sougnez, C., Lichtenstein, L., Cibulskisl, K., Lander, E., Gabriel, S. B., et al. (2015). Comprehensive genomic characterization of head and neck squamous cell carcinomas. Nature 517, 576-582. doi: 10.1038/nature 14129

Lo Muzio, L., Santarelli, A., Caltabiano, R., Rubini, C., Pieramici, T., Trevisiol, L., et al. (2005). p63 overexpression associates with poor prognosis in head and neck squamous cell carcinoma. Hum. Pathol. 36, 187-194. doi: 10.1016/j.humpath.2004.12.003

Mattoscio, D., Casadio, C., Miccolo, C., Maffini, F., Raimondi, A., Tacchetti, C., et al. (2017). Autophagy regulates UBC9 levels during viral-mediated tumorigenesis. PLoS Pathog. 13:e1006262. doi: 10.1371/journal.ppat.10 06262

Melar-New, M., and Laimins, L. A. (2010). Human papillomaviruses modulate expression of microRNA 203 upon epithelial differentiation to control levels of p63 proteins. J. Virol. 84, 5212-5221. doi: 10.1128/JVI.00 078-10

Mighty, K. K., and Laimins, L. A. (2011). p63 is necessary for the activation of human papillomavirus late viral functions upon epithelial differentiation. $J$. Virol. 85, 8863-8869. doi: 10.1128/JVI.00750-11

Napoli, M., Venkatanarayan, A., Raulji, P., Meyers, B. A., Norton, W., Mangala, L. S., et al. (2016). DeltaNp63/DGCR8-dependent microRNAs mediate therapeutic efficacy of HDAC inhibitors in cancer. Cancer Cell 29, 874-888. doi: 10.1016/j.ccell.2016.04.016

Oh, J. E., Kim, R. H., Shin, K. H., Park, N. H., and Kang, M. K. (2011). DeltaNp63alpha protein triggers epithelial-mesenchymal transition and confers stem cell properties in normal human keratinocytes. J. Biol. Chem. 286, 38757-38767. doi: 10.1074/jbc.M111.244939 partially supported by the Italian Ministry of Health with Ricerca Corrente and $5 \times 1000$ funds.

\section{ACKNOWLEDGMENTS}

We thank European Institute of Oncology Biobank.

Oliveira, L. R., Ribeiro-Silva, A., and Zucoloto, S. (2007). Prognostic significance of p53 and p63 immunolocalisation in primary and matched lymph node metastasis in oral squamous cell carcinoma. Acta Histochem. 109, 388-396. doi: 10.1016/j.acthis.2007.03.006

Pozzebon, M. E., Varadaraj, A., Mattoscio, D., Jaffray, E. G., Miccolo, C., Galimberti, V., et al. (2013). BC-box protein domain-related mechanism for VHL protein degradation. Proc. Natl. Acad. Sci. U.S.A. 110, 18168-18173. doi: $10.1073 /$ pnas. 1311382110

Ragin, C. C., Reshmi, S. C., and Gollin, S. M. (2004). Mapping and analysis of HPV16 integration sites in a head and neck cancer cell line. Int. J. Cancer 110, 701-709. doi: 10.1002/ijc.20193

Redon, R., Muller, D., Caulee, K., Wanherdrick, K., Abecassis, J., and du Manoir, S. (2001). A simple specific pattern of chromosomal aberrations at early stages of head and neck squamous cell carcinomas: PIK3CA but not p63 gene as a likely target of 3q26-qter gains. Cancer Res. 61, 4122-4129. Available online at: https://cancerres.aacrjournals.org/content/61/10/4122.full-text.pdf

Reid, P., Wilson, P., Li, Y., Marcu, L. G., Staudacher, A. H., Brown, M. P., et al. (2018). Experimental investigation of radiobiology in head and neck cancer cell lines as a function of HPV status, by MTT assay. Sci. Rep. 8:7744. doi: 10.1038/s41598-018-26134-9

Rocco, J. W., Leong, C. O., Kuperwasser, N., Deyoung, M. P., and Ellisen, L. W. (2006). p63 mediates survival in squamous cell carcinoma by suppression of p73-dependent apoptosis. Cancer Cell 9, 45-56. doi: 10.1016/j.ccr.2005. 12.013

Sabatini, M. E., and Chiocca, S. (2019). Human papillomavirus as a driver of head and neck cancers. Br J Cancer 122, 306-314. doi: 10.1038/s41416-0190602-7

Sandulache, V. C., Wilde, D. C., Sturgis, E. M., Chiao, E. Y., and Sikora, A. G. (2019). A hidden epidemic of "intermediate risk" oropharynx cancer. Laryngosc. Investig. Otolaryngol. 4, 617-623. doi: 10.1002/li o2.316

Sniezek, J. C., Matheny, K. E., Westfall, M. D., and Pietenpol, J. A. (2004). Dominant negative p63 isoform expression in head and neck squamous cell carcinoma. Laryngoscope 114, 2063-2072. doi: 10.1097/01.mlg.0000149437.35855.4b

Srivastava, K., Pickard, A., Mcdade, S., and Mccance, D. J. (2017). p63 drives invasion in keratinocytes expressing HPV16 E6/E7 genes through regulation of Src-FAK signalling. Oncotarget 8, 16202-16219. doi: 10.18632/oncotarge t.3892

Steenbergen, R. D., Hermsen, M. A., Walboomers, J. M., Joenje, H., Arwert, F., Meijer, C. J., et al. (1995). Integrated human papillomavirus type 16 and loss of heterozygosity at 11q22 and 18q21 in an oral carcinoma and its derivative cell line. Cancer Res. 55, 5465-5471.

Stransky, N., Egloff, A. M., Tward, A. D., Kostic, A. D., Cibulskis, K., Sivachenko, A., et al. (2011). The mutational landscape of head and neck squamous cell carcinoma. Science 333, 1157-1160. doi: 10.1126/science.12 08130

Tang, A. L., Hauff, S. J., Owen, J. H., Graham, M. P., Czerwinski, M. J., Park, J. J., et al. (2012). UM-SCC-104: a new human papillomavirus-16-positive cancer stem cell-containing head and neck squamous cell carcinoma cell line. Head Neck 34, 1480-1491. doi: 10.1002/hed.21962

Tomaic, V. (2016). Functional roles of E6 and E7 oncoproteins in HPVinduced malignancies at diverse anatomical sites. Cancers 8:E95. doi: 10.3390/cancers 8100095

Vousden, K. H., and Prives, C. (2009). Blinded by the light: the growing complexity of p53. Cell 137, 413-431. doi: 10.1016/j.cell.2009.04.037

White, J. S., Weissfeld, J. L., Ragin, C. C., Rossie, K. M., Martin, C. L., Shuster, M., et al. (2007). The influence of clinical and demographic 
risk factors on the establishment of head and neck squamous cell carcinoma cell lines. Oral Oncol. 43, 701-712. doi: 10.1016/j.oraloncology.2006. 09.001

Yang, X., Lu, H., Yan, B., Romano, R. A., Bian, Y., Friedman, J., et al. (2011). DeltaNp63 versatilely regulates a Broad NF-kappaB gene program and promotes squamous epithelial proliferation, migration, and inflammation. Cancer Res. 71, 3688-3700. doi: 10.1158/0008-5472.CAN-10-3445

Zangen, R., Ratovitski, E., and Sidransky, D. (2005). DeltaNp63alpha levels correlate with clinical tumor response to cisplatin. Cell Cycle 4, 1313-1315. doi: 10.4161/cc.4.1 0.2066
Conflict of Interest: The authors declare that the research was conducted in the absence of any commercial or financial relationships that could be construed as a potential conflict of interest.

Copyright (c) 2020 Citro, Bellini, Medda, Sabatini, Tagliabue, Chu and Chiocca. This is an open-access article distributed under the terms of the Creative Commons Attribution License (CC BY). The use, distribution or reproduction in other forums is permitted, provided the original author(s) and the copyright owner(s) are credited and that the original publication in this journal is cited, in accordance with accepted academic practice. No use, distribution or reproduction is permitted which does not comply with these terms. 